\title{
SCHEUERMANN'S KYPHOSIS: COMPARISON BETWEEN THE POSTERIOR APPROACH ASSOCIATED WITH SMITH-PETERSEN OSTEOTOMY AND COMBINED ANTERIOR-POSTERIOR FUSION
}

\author{
Eduardo Frois Temponi ${ }^{1}$, Rodrigo D'Alessandro de Macedo ${ }^{2}$, Luiz Olímpio Garcia Pedrosa ${ }^{3}$, Bruno Pinto Coelho Fontes ${ }^{4}$
}

\section{ABSTRACT}

Objective: Surgical treatment of Scheuermann's kyphosis (SK) remains a subject under discussion. In view of the controversy over the best form of surgical tr otomy. Methods: This was a descriptive case-control study with cross-sectional analysis. Twenty-eight patients, split into two groups conducted at different times, were evaluated. Results: The first group comprised patients treated using the double approach, with an average age of 19 years, preoperative kyphosis of $77.6^{\circ}$, postoperative kyphosis of $35.8^{\circ}$ and average correction of $53.2 \%$. The second group comprised patients treated using the posterior route associated with Smith-Petersen osteotomy, with a mean age of 27.3 years, preoperative kyphosis of $72.9^{\circ}$, postoperative kyphosis of $44.3^{\circ}$ and average correction of $39.3 \%$. Analysis between the two groups showed statistically signi- ficant differences in the following variables: age $(p=0.02)$, postoperative kyphosis $(p=0.04)$ and degree and percentage of kyphosis correction $(p=0.001)$. There was no difference concerning preoperative kyphosis $(\mathrm{p}=0.33)$. In the assessment of postoperative pain (VAS), the first group presented an average of 0.6 , versus 0.5 in the second group. There were only minor complications: seven in the first group and two in the second. Conclusion: The two surgical techniques studied proved to be adequate for treating SK. In the present study, the deformity correction was greater in the first group, while the pain VAS results were better in the second group, with lower incidence of complications.

Keywords - Kyphosis; Spine; Scheuermann Disease; Osteotomy; Spinal Fusion

\section{INTRODUCTION}

In 1921, Holger Scheuermann described a kyphotic juvenile vertebral alteration that could be distinguished from postural kyphosis based on its peculiar rigidity $^{(1)}$. He observed that the kyphotic deformity was rigid, and associated with wedging of vertebral bodies ${ }^{(2)}$. Diagnostic criteria were established in 1964 by Sorensen, who came up with a definition of Scheuermann's kyphosis (SK) as a rigid kyphosis that includes three adjacent vertebrae, with wedging of five or more degrees ${ }^{(2)}$. Other criteria were also used, such as an increase in thoracic kyphosis, irregularity of the endplates, increase in disc space and/or characteristic radiographic signs (kyphosis, vertebral wedging, Schmorl's nodes) ${ }^{(3,4)}$. In 1987, Drummond suggested that the diagnosis of the disease be based on adjacent wedging of two or more vertebrae ${ }^{(5)}$. More recently, Bradford modified the previous diagnostic criteria, defining SK as thoracic kyphosis of more than $45^{\circ}$ and at least one wedged vertebra ${ }^{(6)}$ (Figure 1).

1 - Third-year Orthopedics and Traumatology Resident at the Professor Matta Machado Clinic of Hospital Baleia/Fundação Benjamin Guimarães - Belo Horizonte, MG, Brazil.

2 - Coordinator of the Spine Group of Instituto de Previdência dos Servidores de Minas Gerais - IPSEMG. Preceptor of the Spine Group of the Professor Matta Machado Clinic of Hospital da Baleia/Fundação Benjamin Guimarães; Master's Degree in Nuclear Sciences and Techniques from the Department of Nuclear Engineering of Universidade Federal de Minas Gerais - UFMG - Belo Horizonte, MG, Brazil.

3 - Coordinator of the Spine Group of Professor Matta Machado's Service at Hospital da Baleia/Benjamin Guimarães Foundation, Belo Horizonte, MG, Brazil.

4 - Preceptor of the Spine Group of the Professor Matta Machado Clinic of Hospital da Baleia/Fundação Benjamin Guimarães - Belo Horizonte, MG, Brazil.

Study conducted at Professor Matta Machado Orthopedic Clinic of Hospital da Baleia/Fundação Benjamin Guimarães and at Hospital Governador Israel Pinheiro/IPSEMG - Belo Horizonte, MG.

Mailing address: Rua Santa Apolônia, 349, Fernão Dias - 31920-360 - Belo Horizonte, MG. Email: dufrois@hotmail.com

Study received for publication: 3/24/2011, accepted for publication: 7/1/2011.

The authors declare that there was no conflict of interest in conducting this work 
The etiology of SK remains undefined, but is apparently multifactorial in nature, with a dominant autosomal genetic component of high penetrance and variable expressivity, with $74 \%$ heredity ${ }^{(7)}$. Its origin has been associated with avascular necrosis of the epiphyseal rings ${ }^{(1)}$, juvenile osteoporosis ${ }^{(8,9)}$ and cartilaginous matrix disorder, all still with conflicting results. Other etiologies reported include shortening of the ischiotibial musculature ${ }^{(9)}$ and mechanical factors that would trigger secondary remodelling responses, such as reduction of sternal size $\mathrm{s}^{(2,9-12)}$.

According to literature, the incidence of SK ranges from 0.04 to $8.3 \%$ of the population ${ }^{(2,13)}$. It is a deformity that typically occurs at the end of juvenile age, more commonly between eight and 12 years, and occurs in its most rigid form between 12 and 16 years of age. The majority of studies do not show any difference between the sexes, and the incidence in men and women is similar, varying only in terms of the criteria for inclusion of each trial ${ }^{(14,15)}$.

The treatment for SK is still controversial. The tendency is to consider surgical treatment for patients with kyphotic curves of over $75^{\circ}$, with refractory pains on conservative treatment, unacceptable deformities, neurological deficits, and cardiopulmonary impairment ${ }^{(16)}$.

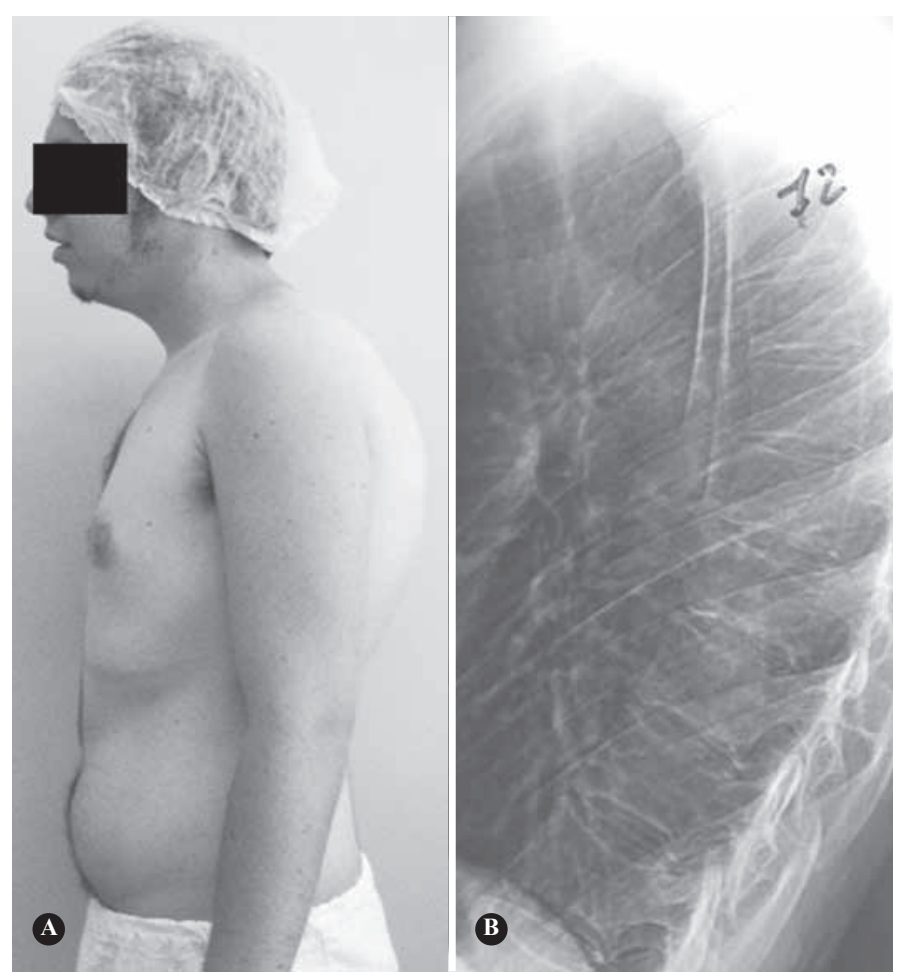

Figure 1 - A) Clinical presentation; and B) Radiographic presentation of Scheuermann's kyphosis.
Isolated posterior arthrodesis presented significant failures, perhaps due to the lack of anterior support, inadequate initial correction, failure of the implant, fixation on the side of the tension, or due to insufficient length of the fixation ${ }^{(12,17)}$. To resolve these problems, dual approach arthrodesis was proposed, with discectomy, release of the anterior-posterior longitudinal ligament, and intersomatic arthrodesis in the first phase of surgery, and arthrodesis and instrumentation in the second phase. Due to the morbidity associated with the dual access, the development of third-generation implants, and materials for their application, associated with average corrections of $59 \%$ of the curves without significant loss, the exclusively posterior approach associated with Smith-Petersen osteotomies has been considered a therapeutic option, already with good results in literature ${ }^{(17-19)}$.

Considering the controversy surrounding the best form of surgical treatment, a study was proposed involving patients diagnosed with SK, to compare the results of treatment using the dual approach (AA + PA) with treatment using posterior approach associated with Smith-Petersen osteotomies (PA + SPO).

The aim of this study is to compare the characteristics of the sample in question, the results of the treatment in terms of the improvement in pain using the VAS, the degree of correction of the deformity, and the patient $>$ s satisfaction with the procedure.

\section{MATERIALS AND METHODS}

The survey was carried out at the Professor Matta Machado Orthopedic Clinic of Hospital da Baleia/ Fundação Benjamin Guimarães and at Hospital Governador Israel Pinheiro of the Instituto de Previdência dos Servidores do Estado de Minas Gerais (IPSEMG). All the patients were submitted to surgical treatment by the same team of surgeons. The proposed study was submitted to, and accepted by the Research Ethics Committee (protocol no. 13/2009). The patients were given instructions and signed a term of consent before taking part in the study.

The diagnostic criteria of SK used were: patients with rigid radiological thoracic kyphosis of over $45^{\circ}$ and at least one wedged vertebra ${ }^{(6)}$. The indications for surgery were: patients with rigid curves of more than $75^{\circ}$, curves of more than $55^{\circ}$ with refractory pain to conservative treatment, and/or major aesthe- 
tic deformity reported by the patient. Patients with flexible thoracic kyphoses, evaluated by means of physical examination and radiography in hyperextension, were excluded, as were patients with kyphosis of other causes.

Due to the wide variation in prevalence of the deformity between populations, and the lack of studies comparing forms of treatment, sample calculation was not possible. Therefore, we opted to use a sample projected to a work of greater international importance, involving 39 patients, which was conducted partly retrospectively and partly prospectively, and published in 2006 by Lee et $a l^{(20)}$. Our sample consisted of 28 patients, divided into two groups, and operated at different times. At the end, the two groups were compared, adopting a comparative, case control methodology with transversal analysis. The first group consisted of patients diagnosed with SK treated with AA + PA, evaluated retrospectively, and the second group consisted of patients treated exclusively with PA + SPO, and operated prospectively.

The first group consisted of a total of 19 patients submitted to surgical treatment with AA + PA for SK in the period from February 2001 to May 2007. The age bracket in this group was 13 to 35 years, with a mean age of 19 years; 19.6 years for the male patients and 17.4 for the female patients. Follow-up time ranged from 12.6 to 61.7 months, with a mean of 37.5 months. The second group consisted of nine patients submitted to surgical treatment with PA + SPO with follow-up from October 2007 to May 2010. The ages ranged from 16 to 51 years, with a mean age of $27.3 ; 24.4$ years for the males and 51 for the female patients. The follow-up time ranged from 13 to 31 months, with a mean of 22.8 months. The distribution of the groups by sex and age is shown in Table 1 .

In the selection of the levels of instrumentation, we considered the proximal level as the vertebra that represented the thoracic kyphosis transition with the cervical lordosis, generally $\mathrm{T} 2$ or $\mathrm{T} 3$, and the distal level of fusion as the most proximal vertebra that touched the posterior sacral vertebral line, generally from L1 to L3.

The patients in the first group were submitted to anterior release by conventional thoracotomy and intersomatic fusion, followed by posterior arthrodesis with posterior instrumentation using the system of
Table 1 - Distribution of patients by sex - group I and II.

\begin{tabular}{c|c|c|c|c}
\hline Sex & $\begin{array}{c}\text { No. of } \\
\text { patients } \\
\text { group I }\end{array}$ & $\begin{array}{c}\text { No. of } \\
\text { patients } \\
\text { group II }\end{array}$ & $\begin{array}{c}\text { Mean age } \\
\text { group I } \\
\text { (years) }\end{array}$ & $\begin{array}{c}\text { Mean age } \\
\text { group II } \\
\text { (years) }\end{array}$ \\
\hline Male & 14.0 & 8.0 & 19.6 & 24.4 \\
\hline Female & 5.0 & 1.0 & 17.4 & 51.0 \\
\hline
\end{tabular}

pedicle screws. The anterior approach was performed by means of left thoracotomy with the patient positioned in right lateral decubitus with costectomy, anterior release (anterior and posterior longitudinal ligament), complete discectomy at the maximum levels necessary and intersomatic arthrodesis without instrumentation of an average of seven discs at the site of the deformity. Only resected rib grafts were placed in the disc spaces. In the period between the two procedures, the patients were kept hospitalized and at rest, without any orthopedic brace and/or traction. After an average of seven days, the patients were submitted to the second surgery, when third generation posterior instrumentation was performed with autologous graft from spinous, transverse and laminous processes. With the patient in ventral decubitus, after a posterior access and subperiosteal dissection, resection of the lower facets was performed at all the levels of arthrodesis (Figure 2).

The intersection of the upper border of the transverse process and the lateral vertical line of the upper articular facet was used as the point of insertion of the pedicle screw ${ }^{(21)}$. Using a $3.2 \mathrm{~mm}$ low-rotation trepan drill, and by manual perception of bone resistance, the drill was advanced slowly, always checking, by small incursions, for the presence of bone at the end of the orifice. A flexible probe was used to confirm the presence of bone in the upper, lower, medial, lateral walls and at the end of the access route ${ }^{(22)}$. The screws were then introduced using the freehand technique - unlike the method reported by Kim et al $l^{(23)}$ in which a drill was used to make the access route ${ }^{(21)}$. Screws were placed bilaterally or unilaterally at each level. The position of the screws was checked by radiographic study in lateral and anterior-posterior views. The stems were moulded and then fixed in the proxi- 


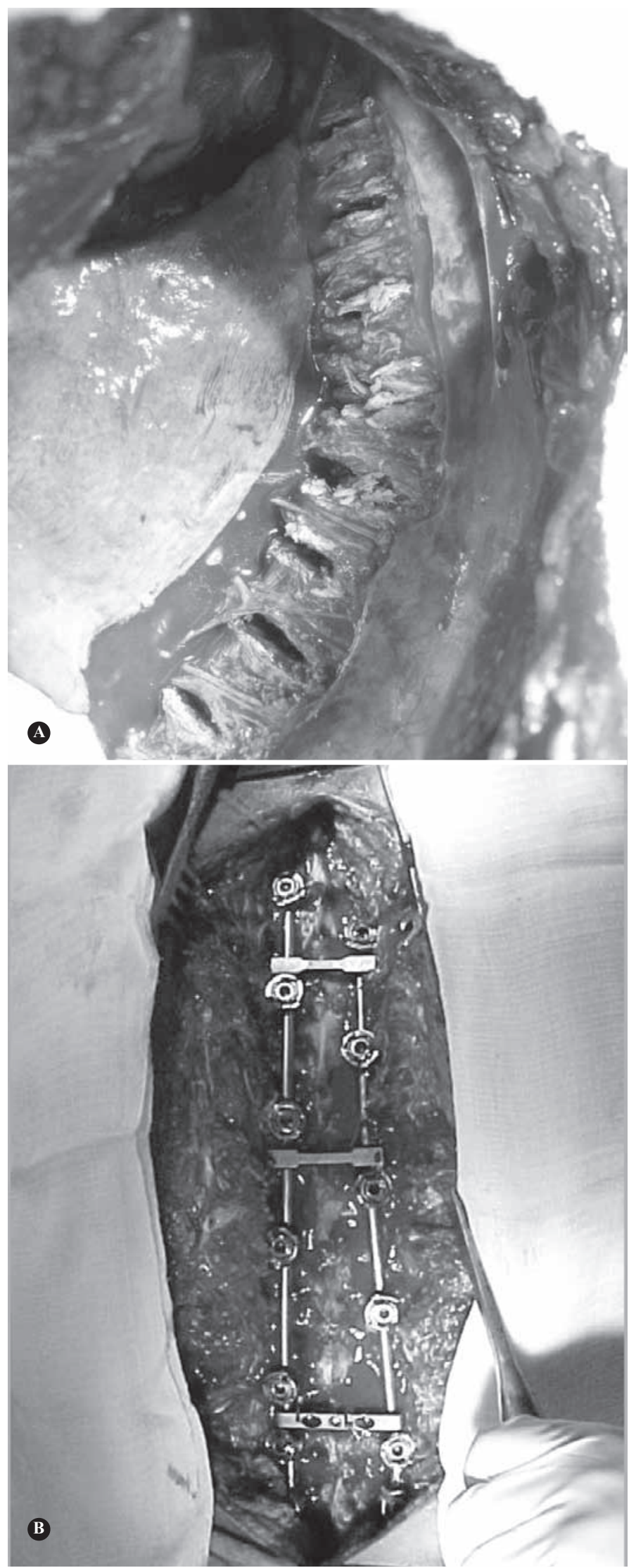

Figure 2 - Dual approach AA + PA: A) Anterior approach with discectomy and arthrodesis without instrumentation; B) Posterior approach with correction of the deformity, instrumentation and arthrodesis. mal segments. Using the "cantilever" manoeuvre, the deformity was reduced and the stems were fixed in the distal segments. Compression manoeuvres were used in the apex of the curve. The number of transversal devices varied as necessary during surgery. In the second group, the instrumentation was performed with posterior arthrodesis, where the difference was due to the osteotomies performed at the apex of the deformity of an average of five segments. After performing the posterior closing-wedge (Smith-Petersen) osteotomies in the segments of the apex of the deformity, the stems were moulded and the deformity was corrected by the same "cantilever" manoeuvre, with compression at the level of the apex (Figure 3).

No somatosensitive monitoring studies or evoked medullary potential studies were carried out in any of the cases due to the lack of available conditions for their performance. All the patients who did not have access to monitoring were submitted to the Stagnara wake-up test, after reduction of the deformity.

No orthopedic brace was used on the patients in the postoperative period.

The patients were followed up every 15 days in the first month after surgery. New evaluations were carried out at three, six, and twelve months after surgery. The evaluations were carried out by members of the team, and consisted of a medical examination and questionnaires to evaluate pain, by the visual analogue scale (VAS), the patients' satisfaction with the procedure, and any complications. The radiological exams were executed for each outpatient control follow-up visit, according to indication.

For the decision as to which statistical tests to perform, the normality of the variables was tested, i.e., whether they followed a normal distribution. With an error of five percent, the variables sex, initial kyphosis, final kyphosis, correction (degrees) and follow-up (months) followed a normal distribution. The variables age, level of posterior fusion, and number of screws did not follow this behaviour. Thus, for the variables that were considered normal, a parametric test will be used, in this case, the T-test, to test whether there is any difference between the means of the variables. For the non-normal variables, a nonparametric test will be used, the Mann-Whitney test. The purpose of this treatment is to level out the sample and avoid any statistical bias. 


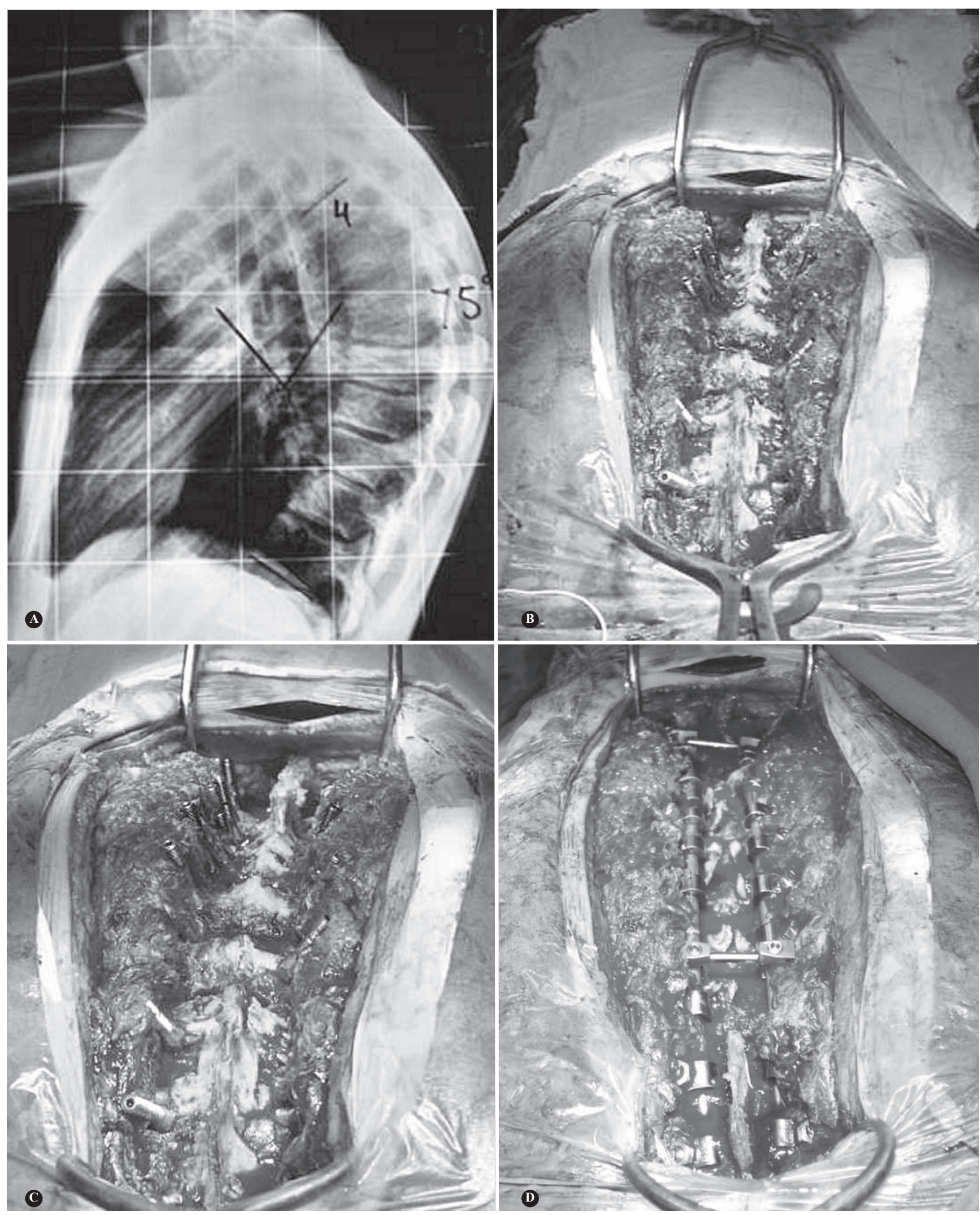

Figure 3 - Exclusively posterior approach associated with Smith-Petersen osteotomies (PA + SPO): A) Radiographic presentation of the deformity; B) Posterior approach with introduction of screws under fluoroscopic guidance; C) Smith-Petersen osteotomies at the apex of the deformity; D) Introduction of the stem and correction of the deformity. 


\section{RESULTS}

There was no statistical difference between the sexes of both groups $(p=0.2)$. Comparing the ages of both groups, a statistical difference was noted $(p=0.02)$. The comparison between the degree of initial and final average kyphosis between the sexes of both groups is shown in table 2 .

In the preoperative evaluation of the patients in the first group, the degree of thoracic kyphosis ranged from $66^{\circ}$ to $94^{\circ}$ with an average of $77.6^{\circ}$. After the postoperative follow-up, the degree of kyphosis found in the patients was $23^{\circ}$ to $50^{\circ}$, with an average of $35.8^{\circ}$ (Table 3).

In the evaluation of the second group, the degree of kyphosis in the preoperative period ranged from $57^{\circ}$ to $90^{\circ}$, with an average of $77.58^{\circ}$. After the posterior approach, an average correction of $28.56^{\circ}$ was obtained, with a degree of final kyphosis ranging from $33^{\circ}$ to $60^{\circ}$, and an average of $44.3^{\circ}$ (Table 4 ).

In the comparative analysis between the two groups (Table 5), there was statistical significance for the variables age $(p=0.02)$, postoperative kyphosis $(p=0.04)$, and the degree and percentage of correction of the kyphosis $(p=0.001)$, but there were no differences for preoperative kyphosis $(p=0.33)$.

Of the patients in the first group, 17 had preoperative pain. The average score obtained in the preoperative evaluation was 6.6. After follow-up, the patients were evaluated by the same VAS method; only three

Table 2 - Comparison between the sexes in the evolution of degree of kyphosis.

\begin{tabular}{|c|c|c|c|c|c|c|}
\hline Sex & $\begin{array}{c}\text { Mean initial kyphosis } \\
\text { group I (degree) }\end{array}$ & $\begin{array}{c}\text { Mean initial kyphosis } \\
\text { group II (degree) }\end{array}$ & $\begin{array}{c}\text { Mean final kyphosis } \\
\text { group I (degree) }\end{array}$ & $\begin{array}{c}\text { Mean final } \\
\text { kyphosis group II } \\
\text { (degree) }\end{array}$ & $\begin{array}{c}\text { Mean } \% \text { correction } \\
\text { group I }\end{array}$ & $\begin{array}{c}\text { Mean } \% \text { correction } \\
\text { group II }\end{array}$ \\
\hline Male & $75.4^{\circ}$ & $70.8^{\circ}$ & $37.5^{\circ}$ & $43.4^{\circ}$ & $50.3^{\circ}$ & $38.7^{\circ}$ \\
\hline Female & $83.8^{\circ}$ & $90^{\circ}$ & $31.2^{\circ}$ & $52^{\circ}$ & $62.8^{\circ}$ & $38^{\circ}$ \\
\hline
\end{tabular}

Table 3 - Results of the treatment - group I.

\begin{tabular}{|c|c|c|c|c|c|c|c|}
\hline Patient & $\begin{array}{c}\text { Age } \\
\text { (years) }\end{array}$ & Sex & $\begin{array}{c}\text { Initial } \\
\text { kyphosis } \\
\text { (degree) }\end{array}$ & $\begin{array}{c}\text { Final } \\
\text { kyphosis } \\
\text { (degree) }\end{array}$ & $\begin{array}{c}\text { Level of } \\
\text { posterior } \\
\text { fusion }\end{array}$ & $\begin{array}{l}\text { Follow-up } \\
\text { (months) }\end{array}$ & $\begin{array}{l}\text { No. of } \\
\text { screws }\end{array}$ \\
\hline 1 & 15 & $M$ & 86 & 40 & T2-L2 & 61.7 & 12 \\
\hline 2 & 21 & $M$ & 82 & 48 & T3-L3 & 55.1 & 16 \\
\hline 3 & 33 & $M$ & 80 & 50 & T2-L2 & 48.8 & 20 \\
\hline 4 & 22 & $F$ & 72 & 23 & T2-L3 & 48.4 & 20 \\
\hline 5 & 16 & M & 72 & 28 & T4-L2 & 51.9 & 13 \\
\hline 6 & 16 & M & 66 & 30 & T2-L1 & 51.6 & 11 \\
\hline 7 & 18 & $M$ & 90 & 30 & T3-L3 & 46.5 & 18 \\
\hline 8 & 13 & $M$ & 60 & 40 & T4-L2 & 43.9 & 14 \\
\hline 9 & 16 & $F$ & 90 & 30 & T3-L2 & 47.6 & 15 \\
\hline 10 & 20 & $M$ & 82 & 40 & T3-L3 & 45.1 & 14 \\
\hline 11 & 17 & $F$ & 78 & 32 & T4-L2 & 26.7 & 15 \\
\hline 12 & 15 & $M$ & 65 & 30 & T3-L2 & 36.6 & 16 \\
\hline 13 & 21 & $M$ & 60 & 45 & T2-L2 & 36.2 & 16 \\
\hline 14 & 35 & $M$ & 86 & 48 & T3-L2 & 21.5 & 15 \\
\hline 15 & 16 & $M$ & 69 & 28 & T3-L2 & 18.5 & 19 \\
\hline 16 & 16 & $F$ & 94 & 35 & T2-L2 & 25.4 & 16 \\
\hline 17 & 16 & $\mathrm{~F}$ & 85 & 36 & T2-L2 & 14.2 & 16 \\
\hline 18 & 16 & $\mathrm{M}$ & 72 & 28 & T2-L2 & 12.6 & 19 \\
\hline 19 & 19 & $M$ & 85 & 40 & T2-L2 & 19.7 & 16 \\
\hline Mean & 19 & NA & 77.6 & 35.8 & NA & 37.5 & 15.8 \\
\hline
\end{tabular}

Caption: NA - not applicable; M - male; F - Female.
Table 4 - Results of the treatment - group II.

\begin{tabular}{c|c|c|c|c|c|c|c}
\hline Patient & $\begin{array}{c}\text { Age } \\
\text { (years) }\end{array}$ & Sex & $\begin{array}{c}\text { Initial } \\
\text { kyphosis } \\
\text { (degree) }\end{array}$ & $\begin{array}{c}\text { Final } \\
\text { kyphosis } \\
\text { (degree) }\end{array}$ & $\begin{array}{c}\text { Level of } \\
\text { posterior } \\
\text { fusion }\end{array}$ & $\begin{array}{c}\text { Follow-up } \\
\text { (months) }\end{array}$ & $\begin{array}{c}\text { No. of } \\
\text { screws }\end{array}$ \\
\hline 1 & 19 & M & 58 & 38 & T4-L1 & 31 & 20 \\
\hline 2 & 30 & M & 78 & 45 & T3-L2 & 29 & 20 \\
\hline 3 & 28 & M & 72 & 48 & T2-L2 & 26 & 26 \\
\hline 4 & 20 & M & 66 & 35 & T3-L3 & 18 & 16 \\
\hline 5 & 20 & M & 75 & 54 & T3-T12 & 21 & 16 \\
\hline 6 & 43 & M & 90 & 60 & T2-L3 & 28 & 28 \\
\hline 7 & 51 & F & 90 & 52 & T3-L2 & 25 & 22 \\
\hline 8 & 19 & M & 70 & 33 & T4-L3 & 15 & 16 \\
\hline 9 & 16 & M & 57 & 34 & T3-L1 & 13 & 15 \\
\hline Mean & 27.3 & NA & 72.8 & 44.3 & NA & 22.8 & 179 \\
\hline & & & \multicolumn{5}{|c}{}
\end{tabular}

Table 5 - Comparative analysis of surgical approaches.

\begin{tabular}{|c|c|c|c|}
\hline & Dual access & Posterior approach & $P$ value \\
\hline Mean age* (SD) & $\begin{array}{c}19.0 \text { years } \\
( \pm 5.8)\end{array}$ & 27.33 years $( \pm 12.2)$ & $0.02^{*}$ \\
\hline \multicolumn{4}{|l|}{ Maximum kyphosis } \\
\hline Preoperative (SD) & $77.6( \pm 10.4)$ & $72.9( \pm 12.0)$ & 0.33 \\
\hline Postoperative (SD) & $35.8( \pm 8.0)$ & $44.3( \pm 9.8)$ & $0.04^{*}$ \\
\hline \multicolumn{4}{|l|}{ Correction } \\
\hline${ }^{\circ}$ Postoperative (SD) & $41.7( \pm 12)$ & $28.6( \pm 6)$ & $0.001^{*}$ \\
\hline \% Postoperative (SD) & $53.2( \pm 11.9)$ & $39.3( \pm 7.8)$ & $0.001^{*}$ \\
\hline
\end{tabular}

i.e., there is a difference between the groups $(p<0.05)$. 
patients complained of residual pain, and the average postoperative score was 0.6 . In the second group, eight patients presented preoperative pain, with an average score of 5.6. After the follow-up, only one patient complained of residual pain, and the final average score was 0.5 .

In terms of patient satisfaction with the surgical procedure, $94.7 \%$ of those in the first group were satisfied, and just one was dissatisfied, reporting that they would not submit again to the surgical intervention if indicated to do so. In the second group, patient satisfaction was $100 \%$.

In terms of complications associated with the procedures, the following were identified for the first group: one case of early surface infection of the surgery wound, treated with oral antibiotic in outpatient regimen; one case of asymptomatic breaking of two screws; one case of late infection at 24 months after surgery, which was resolved with the removal of the implant without losing the correction of the deformity; one case of loosening of the distal implant, requiring a new surgical intervention with extension of the level of the arthrodesis; three patients with complaint of residual pain, and two of these patients reported sporadic pain, which did not require any treatment. The second group presented a case of residual pain of lesser intensity than in the preoperative period, one case of seroma in the postoperative period, improving with local measures, and one case of discomfort at the site of the implants, opting to remove them two years after the procedure, with resolution of the pain.

\section{DISCUSSION}

The treatment of SK remains controversial. Since Bradford et $a l^{(24)}$ carried out the first report on posterior fusion in the treatment of SK, the surgical indications, as well as the operating techniques, have altered significantly. In various case series, pain and deformity are adopted as the criteria for surgical indication $^{(4,22,24)}$. Some studies indicate surgery for cases of pain that is refractory to conservative treatment ${ }^{(25,26)}$. Lowe recommends surgery in SK in adults with kyphosis greater than or equal to $75^{\circ}$, where there is persistent pain, despite conservative treatment, and in those with deformities affecting the patient's aesthetic appearance ${ }^{(25)}$. Murray et $a l^{(15)}$ reserve the surgical option only for cases of unacceptable pain and deformity. The criteria used in this study were in keeping with literature.
The efficacy of combined treatment of SK by the anterior and posterior route is well documented in literature. Bradford et $a l^{(24)}$, in 1980, described average correction of $77^{\circ}$ to $41^{\circ}$ at the end of the procedure, and $47^{\circ}$ at the end of the follow-up of 24 patients. Herndon et $a l^{(27)}$ evaluated the results of dual access in 13 patients with release and anterior arthrodesis followed by posterior fusion, obtaining average correction of $51^{\circ}$ and satisfactory pain relief in 12 patients. Lowe ${ }^{(25)}$ analyzed 24 patients submitted to the anterior approach with posterior fusion, and obtained good results without significant loss of correction or complications at the end of the 19-month follow-up. Lim et $a l^{(28)}$, evaluating 23 patients, described correction of $37^{\circ}$ at the end of the procedure, and $32^{\circ}$ at the end of the follow-up. In our study, we retrospectively operated on 19 patients with initial average kyphosis of $77.6^{\circ}$ through the dual approach, over a period of 37.5 months, obtaining $53.2 \%$ correction at the end of the treatment (average $41.7^{\circ}$ ).

In relation to the posterior approach in isolation, the debate still continues, as the results of literature are conflicting. The first reports came from Bradford et $a l^{(14)}$; but with loss of good results of correction in 16 of the 22 patients. Papagelopoulos et al ${ }^{(29)}$ compared the treatment in 13 patients submitted to posterior instrumentation versus eight patients treated by the dual approach route, obtaining a correction rate of $42 \%\left(68.5^{\circ}\right.$ to $\left.40^{\circ}\right)$ with loss of correction in this group of $5.8^{\circ}$ over 4.5 years of follow-up. Otsuka et $a l^{(26)}$, with the posterior approach using the system of Harrington, obtained average correction of $45 \%$ $\left(71.4^{\circ}\right.$ to $\left.39.3^{\circ}\right)$ with a loss rate of $7.8 \%$. Johnston et $a l^{(30)}$, in a retrospective study, evaluated 27 patients divided into two groups based on the dual approach, and the posterior approach $(46 \% \times 53 \%)$. There was no difference in the correction obtained after surgery or after end of the follow-up. Lee et al ${ }^{(20)}$ compared 18 patients with SK submitted to posterior spinal fusion using a pedicle screw with 21 patients in whom anterior-posterior fusion was carried out through the use of combined constructions using hooks or screws/ hooks. In the first group, the average degree of correction was $52 \%$ after a mean follow-up time of 31.7 months, while in the second group of patients, the average correction was $54.6 \%$, after a mean follow-up of 67.5 months $^{(20)}$. In the present study, the patients 
in whom the posterior approach was used had a mean follow-up of 22.8 months, with initial kyphosis of $72.9^{\circ}$ and a final average of $44.3^{\circ}$, obtaining $39.3 \%$ of correction (28.6 $6^{\circ}$ average correction).

Lim et $a l^{(28)}$, in a retrospective follow-up of 23 patients, 20 treated by the dual route and three by the posterior route, obtained $43 \%$ of minor complications, $17 \%$ of major complications, and $0 \%$ of life-threatening complications. Two other studies evaluating the posterior approach using the hook system showed loosening of the hooks in three cases out of 27, requiring two subsequent surgeries ${ }^{(4)}$; in the other study, there was breaking of the stem in one case out of 30 , requiring revision surgery and resulting in one patient with loss of correction, and pain ${ }^{(31)}$. In the series of Lee et $a l^{(20)}$ there were no complications related to the instrumentation. In our series, we demonstrated seven complications in the group in which the double approach was used (one case of early surface infection of the surgery wound; one case of asymptomatic breaking of two screws; on case of late infection 24 months after surgery; one case of loosening of the distal implant; and three patients with complaints of residual pain), and only three in the group in which the posterior route was used (one case of residual pain, another of discomfort around the implants, and another with a wound seroma after surgery). The frequency of complications varies depending on the criteria adopted by the researchers, but this has not been validated.

In the comparative evaluation of the two groups in this study, better correction of the deformity was found in the cases operated by the traditional technique (AA + PA), with statistical difference in the postoperative curves, and in the degree and percentage of correction of the deformity $(p=0.01)$. This may be explained by the learning curve required for the new technique, the incipient number of patients in which the second technique was used, and perhaps, the presence of older patients, with more rigid curves, in the posterior approach group. There were no differences between the sexes in the comparison between the two groups; however, there was a distinction for the variable age, with group II (PA + SPO) being, on average, eight years older, a fact that was also demonstrated in the work of Lee et $a l^{(20)}$. Although not tested statistically, there was a higher absolu- te number of complications, though less severe, in group I, with higher levels of satisfaction achieved in group II. No valid questionnaire of satisfaction and improvement in quality of life was applied in this study; however, for the next follow-up, the SRS-22 questionnaire will be applied.

The results of this study demonstrate the importance of study with randomized, prospective follow-up with greater homogenization of the samples, to adequately determine which is the best choice in terms of approach. However, these choices are hampered by the minor prevalence of the disease, and the restricted criteria for surgical indication.

The posterior approach associated with osteotomies has been a recent option, given the association between technical improvements (osteotomies) and the development of fixation systems, resulting in shorter surgery times, and fewer comorbidities and associated complications (blood transfusion, decrease in pulmonary capacitance, hospitalization times, and recovery times). The objective of any correction is to offer the patient an improvement in sagittal and coronal balance, centralizing the whole segment above the pelvis, and this has been achieved by means of a single approach. Although there was no objective control in this study, it was noted that there were less systemic repercussions in patients when this approach route was used, with faster, less painful rehabilitation. We highlight the fact that the sample is still small, and the need for longer follow-up of cases, following surgery, as well as better training in the practice of osteotomies, and new studies to evaluate the real role of posterior instrumentation associated with SmithPetersen osteotomy as a method of treating SK.

\section{CONCLUSION}

The two surgical techniques studied proved to be adequate for the treatment of Scheuermann's kyphosis. In the present study, we observed greater correction of the deformity with the double approach, while in the second group there were better results in the VAS pain scale, and a lower percentage of complications. For a more viable result, a program of prospective, randomized work is needed, to homogenize the groups and eliminate differences in the sample. 


\section{REFERENCES}

1. Scheuermann HW. Kyphosis dorsalis juvenilis. Orthop Chir. 1921;41:305-17.

2. Sorensen KH. Scheuermann's Juvenile Kyphosis: clinical appearances, radiography, aetiology and prognosis. Copenhagen: Munksgaard; 1964.

3. Stoddasd A, Osborn JF. Scheuermann's disease or spinal osteochondrosis: its frequency and relationship with spondylosis. J Bone Joint Surg $\mathrm{Br}$. 1979;61(1):56-8.

4. Taylor TC, Wenger DR, Stephen J, Gillespie R, Bobechko WP. Surgical management of thoracic kyphosis in adolescents. J Bone Joint Surg Am. 1979;61(4):496-503.

5. Ali RM, Green DW, Patel TC. Scheuermann's kyphosis. Curr Opin Pediatr. 1999;11(1):70-5.

6. Bradford DS. Juvenile kyphosis. In: Lonstein JE, Bradford DS, Winter RB, Ogilvie J. Moe's textbook of scoliosis and other spinal deformities. 3rd ed. Philadelphia: Saunders; 1995. p. 349-67.

7. Damborg F, Engell V, Andersen M, Kyvik KO, Thomsen K. Prevalence, concordance, and heritability of Scheuermann kyphosis based on a study of twins. J Bone Joint Surg Am. 2006;88(10):2133-6.

8. Gilsanz V, Gibbens DT, Carlson M, King J. Vertebral bone density in Scheuermann disease. J Bone Joint Surg Am. 1989;71(6):894-7.

9. Lopez RA, Burke SW, Levine DB, Schneider R. Osteoporosis in Scheuermann's disease. Spine. 1988;13(10):1099-103

10. Lowe TG. Scheuermann disease. J Bone Joint Surg Am. 1990;72(6):940-5.

11. Aufdermaur M. Juvenile kyphosis (Scheuermann's disease): radiography, histology, and pathogenesis. Clin Orthop Relat Res. 1981;(154):166-74.

12. Ferguson $A B$ Jr. The etiology of preadolescent kyphosis. J Bone Joint Surg Am. 1956;38(1):149-57

13. Scoles PV, Latimer BM, Diglovanni BF, Vargo E, Bauza S, Jellema LM. Vertebral alterations in Scheuermann's kyphosis. Spine. 1991;16(5):509-15.

14. Bradford DS, Moe JH, Montalvo FJ, Winter RB. Scheuermann's kyphosis. Results of surgical treatment by posterior spine arthrodesis in twenty-two patients. J Bone Joint Surg Am. 1975;57(4):439-48.

15. Murray PM, Weinstein SL, Spratt KF. The natural history and long-term follow-up of Scheuermann kyphosis. J Bone Joint Surg Am. 1993;75(2):236-48.

16. Tribus CB. Scheuermann's kyphosis in adolescents and adults: diagnosis and management. J Am Acad Orthop Surg. 1998;6(1):36-43.

17. Gill JB, Levin A, Burd T, Longley M. Corrective osteotomies in spine surgery. J Bone Joint Surg Am. 2008;90(11):2509-20.

18. Berven SH, Deviren V, Smith JA, Hu SA, Bradford DS. Management of fixed sagittal plane deformity: outcome of combined anterior and posterior surgery. Spine (Phila Pa 1976). 2003;28:1710-16
19. Bridwell KH. Decision making regarding Smith-Petersen vs. pedicle subtraction osteotomy vs. vertebral column resection for spinal deformity. Spine (Phila Pa 1976). 2006;31(19 Suppl):S171-8.

20. Lee SS, Lenke LG, Kuklo TR, Valenté L, Bridwell KH, Sides B, Blanke KM. Comparison of Scheuermann kyphosis correction by posterior-only thoracic pedicle screw fixation versus combined anterior/posterior fusion. Spine (Phila Pa 1976). 2006;31(20):2316-21.

21. Macedo RD, Fontes BPC, Cunha FM, Werlang PM. Sistema de parafusos pediculares no tratamento de deformidades vertebrais: analise da correção e das complicações imediatas. Rev Bras Ortop. 2006;41(10):417-24.

22. Suk SI, Kim WJ, Lee SM, Kim JH, Chung ER. Thoracic pedicle screw fixation in spinal deformities: are they really safe? Spine (Phila Pa 1976). 2001;26(18):2049-57.

23. Kim YJ, Lenke LG, Bridwell KH, Cho YS, Riew KD. Free hand pedicle screw placement in the thoracic spine: is it safe? Spine (Phila Pa 1976). 2004;29(3):333-42.

24. Bradford DS, Ahmed KB, Moe JH, Winter RB, Lonstein JE. The surgical management of patients with Scheuermann's disease: a review of twenty-four cases managed by combined anterior and posterior spine fusion. J Bone Joint Surg Am. 1980;62(5):705-12.

25. Lowe TG. Double L-rod instrumentation in the treatment of severe kyphosis secondary to Scheuermann's disease. Spine (Phila Pa 1976). 1987;12(4):336-41.

26. Otsuka NY, Hall JE, Mah JY. Posterior fusion for Scheuermann's kyphosis. Clin Orthop Relat Res. 1990;(251):134-9.

27. Herndon WA, Emans JB, Micheli LJ, Hall JE. Combined anterior and posterio fusion for Scheuermann's kyphosis. Spine (Phila Pa 1976). 1981;6(2):125-30.

28. Lim M, Green DW, Billinghurst JE, Huang RC, Rawlins BA, Widmann RF, Burke SW, Boachie-Adjei O. Scheuermann kyphosis: safe and effective surgical treatment using multisegmental instrumentation. Spine (Phila Pa 1976). 2004;29(16):1789-94

29. Papagelopoulos PJ, Klassen RA, Peterson HA, Dekutoski MB. Surgical treatment of Scheuermann's disease with segmental compression instrumentation. Clin Orthop Relat Res. 2001;(386):139-49.

30. Johnston CE 2nd, Elerson E, Dagher G. Correction of adolescent hyperkyphosis with posterior-only threaded rod compression instrumentation: is anterior spinal fusion still necessary? Spine (Phila Pa 1976). 2005;30(13):1528-34.

31. Sturm PF, Dobson JC, Armstrong GW. The surgical management of Scheuermann's disease. Spine (Phila Pa 1976). 1993;18:685-91. 


\section{Errata}

In volume 46, issue no. 6 , of the journal RBO (November/December), in the article "Scheuermann's Kyphosis: comparison between the posterior approach associated with Smith-Petersen osteotomy and combined anterior-posterior fusion", on page 709, where it reads: dufrois@gotimail.com, the correct address is dufrois@hotmail.com.

Furthermore, in the titles and affiliations of the author Luiz Olimpio Garcia Pedrosa, where it reads: "Third-year Resident Physician of Orthopedics and Traumatology of Professor Matta Machado's Service at Hospital da Baleia/Benjamin Guimarães Foundation, Belo Horizonte, MG, Brazil", the correct title is "Coordinator of the Spine Group of Professor Matta Machado's Service at Hospital da Baleia/Benjamin Guimarães Foundation, Belo Horizonte, MG, Brazil. 